\title{
Erratum to: Women-only drug treatment services and needs in Iran: the first review of current literature
}

\author{
Zahra Alam-mehrjerdi ${ }^{1}$, Reza Daneshmand ${ }^{2 *}$, Mercedeh Samiei ${ }^{3}$, Roya Samadii ${ }^{4}$ Mohammad Abdollahi ${ }^{5}$ \\ and Kate Dolan ${ }^{1}$
}

\section{Erratum}

Following publication of the original article in DARU Journal of Pharmaceutical Sciences [1], it was brought to our attention that the following sentences are incorrect:

"Smoking opium has a long history in Iran which dates back hundreds of years before the tribal Arab invasion to Iran." The sentence should read: Smoking opium has a long history in Iran which dates back hundreds of years before the brilliant era of Zoroaster.

"Therefore, a center for at-risk women was established in Shiraz and Esfahan near the Persian Gulf of Iran in 2007." This sentence should read: Therefore, two centers for at-risk women were established in Shiraz and Esfahan near the Persian Gulf of Iran in 2007.

"In addition, such programs are needed to address special needs of at-risk women such as trauma, rape or poly drug use $[45,46]$." This sentence should read: In addition, such programs are needed to address special problems of at-risk women such as trauma, rape or poly drug use $[45,46]$.

Also, the header "Motivation for treatment entry and positive treatment outcome" should read: Motivations for treatment entry and positive treatment outcomes.

We apologize for the inconvenience.
Received: 1 May 2016 Accepted: 6 July 2016

Published online: 25 July 2016

\section{Reference}

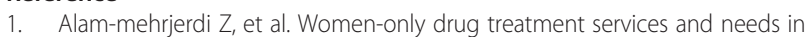
Iran: the first review of current literature. DARU Journal of Pharmaceutical Sciences. 2016;24:3.

\begin{abstract}
Author details
${ }^{1}$ Program of International Research and Training, National Drug and Alcohol Research Centre, Faculty of Public Health and Community Medicine, University of New South Wales, Sydney, Australia. ${ }^{2}$ Substance Abuse and Dependence Research Center, University of Social Welfare and Rehabilitation Sciences, Tehran, Iran. ${ }^{3}$ Department of Psychiatry, School of Behavior Sciences, University of Social Welfare and Rehabilitation Sciences, Tehran, Iran. ${ }^{4}$ Psychiatry and Behavioral Sciences Research Center, Department of Psychiatry, Mashhad University of Medical Sciences, Mashhad, Iran. ${ }^{5}$ Department of Toxicology and Pharmacology, Faculty of Pharmacy and Pharmaceutical Sciences Research Center, Tehran University of Medical Sciences, Tehran, Iran.
\end{abstract}

\footnotetext{
* Correspondence: prof.reza.daneshmand@gmail.com; re.daneshmand@uswr.ac.ir ${ }^{2}$ Substance Abuse and Dependence Research Center, University of Social Welfare and Rehabilitation Sciences, Tehran, Iran

Full list of author information is available at the end of the article
}

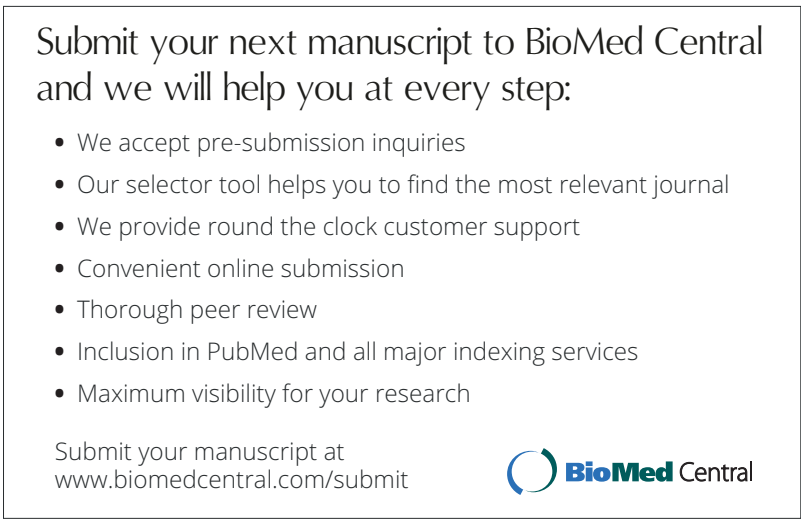

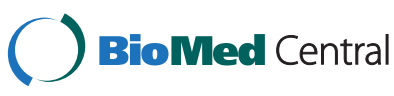

(c) 2016 The Author(s). Open Access This article is distributed under the terms of the Creative Commons Attribution 4.0 International License (http://creativecommons.org/licenses/by/4.0/), which permits unrestricted use, distribution, and reproduction in any medium, provided you give appropriate credit to the original author(s) and the source, provide a link to the Creative Commons license, and indicate if changes were made. The Creative Commons Public Domain Dedication waiver (http://creativecommons.org/publicdomain/zero/1.0/) applies to the data made available in this article, unless otherwise stated. 